\title{
The study of the collapse zone by remote methods
}

\author{
Oleksandr Dolgikh*, and Liubov Dolgikh
}

Kryvyi Rih National University, Department of Mine Surveying, 11 Vitalii Matusevych Str., Kryvyi Rih, 50027, Ukraine

\begin{abstract}
The aim of the research is to choose an effective remote method for surveying the area located above the space mined by underground mining. Often in separate sections of these territories funnels and dips are formed that do not allow the use of methods with finding the performer directly at these potentially dangerous sites. The research methodology is based on the implementation of survey work in the territory of the Ordzhonikidze mine, where underground mining is influencing the state of the ground surface and buildings. In this case, various remote survey methods were used. An analysis of the results of the survey work made it possible to determine the most effective method for studying dangerous areas in which horizontal and vertical deformations are observed. As a result of research, special attention was paid to the use of modern remote sensing methods for the territory of the mine. As a result of the analysis of the survey using remote methods, the expediency of applying the method of terrestrial stereo survey is determined, which has the necessary accuracy, and at the same time it is quite operational. The scientific novelty of the obtained results lies in the fact that the effectiveness of the use of ground-based digital stereo survey for studying the deformations of the ground surface and objects located in the mine and adjacent areas that are undermined by underground mining has been proved. The optimal conditions for performing stereo survey of the ground surface and objects of these territories are determined, and a scheme for performing the binding of survey stations is selected. The practical significance of the research is to study the deformations of the ground surface and buildings on the mine territory and adjacent areas, terrestrial digital stereo survey was used, which made it possible to quickly determine horizontal and vertical deformations for a large number of points with the necessary accuracy.
\end{abstract}

\section{Introduction}

The study of deformations of the ground surface and objects is an important task that many scientists and practitioners are involved in [1-5]. With the improvement of surveying and geodetic instruments and software for them, the level of research is being increased [6].

To increase the stability of underground mine workings, effective development systems are developed and implemented, which allows to increase the safety of mining operations and to ensure minimal impact on the ground surface and objects located on it $[7,8]$.

The mine surveying service of the mining enterprise constantly monitors the deformations to which the ground surface and structures on it are exposed due to underworking by their mining operations. In coal deposits, surface deformations are characterized by insignificant values - millimeters, and in the development of ore deposits, their sizes can reach meters. It is known that such deformations often form zones of funnels, terraces, cracks, and smooth movement. The performed studies are devoted to issues of remote monitoring of the funnel zone and observations of the stability of the slopes of the formed failures, using the example of the Ordzhonikidze mine, where in 2010 the collapse was accompanied by the formation of a funnel with an area of 17 hectares.

\section{Analysis of remote deformation observation methods}

Undoubtedly, the method that gives the most comprehensive information is aerosurveying, but it is not sufficiently informative in the study of vertical slopes [911]. Therefore, other remote methods can additionally be used:

- visual inspection;

- use of reflectorless total stations;

- laser scanning;

- scanning based on the use of interferometry;

- ground photogrammetric survey.

Visual inspection is an important priority measure, however, even the use of magnifying optics can only determine the fact of the most significant deformations in the form of cracks and landslides, but it does not make it possible to determine the metric characteristics of the processes. It is the detection of cracks during visual inspection that justifies the implementation of further instrumental studies. Today, from a distance of 650-700 meters visually determine the nature, size and dynamics

${ }^{*}$ Corresponding author: dlavgeod@gmail.com 
of deformations, even approximately, it seems impossible.

Reflectorless total station is the simplest method that does not require special training and can be performed by an ordinary mine surveyor of a mining enterprise. 10 years ago, electronic total stations with a reflectorless mode up to $1000 \mathrm{~m}$ were very expensive and therefore rare. But by the time of the collapse of 2010, the surveying service of the Central GOK had a similar Topcon GPT-3000 device for operation. The first studies of the danger zone in the Ordzhonikidze mine started almost immediately after the collapse, and were performed by this total station by specialists of the mine surveying department of the plant, together with the researchers of the mine surveying department of Kryvyi Rih National University. The use of electronic total stations at the mining enterprises of Krivbass has its own specifics. Dark rocks absorb the rays strongly, and the total station, with a passport value of the reflectorless mode of 1000 meters, actually measures the distance up to 600-650 meters. Naturally, this is not about the characteristics of the device or its malfunction, but about the influence of rocks on the measuring process. This total station without any problems measures the distance to bright objects, for example, to a white wall or a light strip on a chimney at a distance of 980 meters, although it consumes a huge amount of energy, which significantly reduces the battery life. The decrease in the range of the reflectorless mode introduced its own corrections into the observation program, namely, it contributed to an increase in the number of points of polygonometric moves, from the points of which the survey was directly performed. The binding of polygon moves was carried out to the points of the state geodetic network of this region, which are outside the zone of influence of mining operations.

Using the reflectorless mode of the total station, for several days of work the coordinates of 332 points were determined, the total number of which includes not only reference points, but also points of polygonometric moves (Fig. 1, 2).

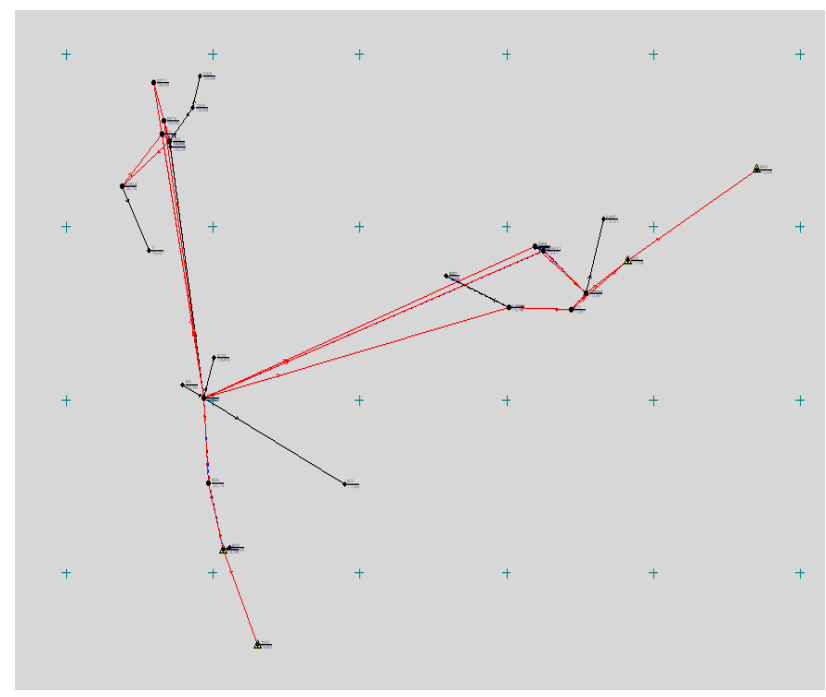

Fig. 1. The scheme of binding moves.

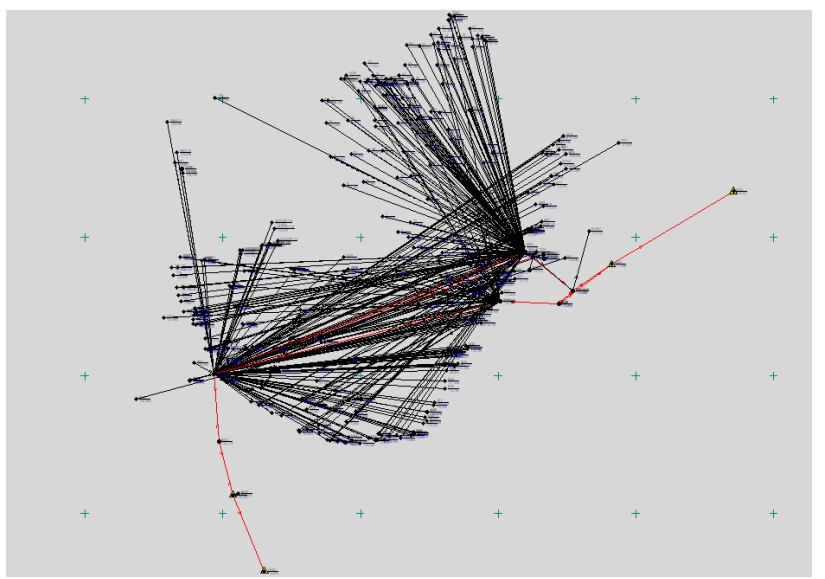

Fig. 2. The scheme of surveying using a reflectorless total station.

As a result of studies, it was confirmed that the use of the method of reflectorless total station in the quarry has significant disadvantages: the presence of a large number of dead zones; the inability to do surveying work in some areas because of the danger of being on them or because of the presence of dense vegetation.

Also a remote method is laser scanning. Laser scanners at the time of the release of the crow in 2010 had a high cost and, at the same time, parameters that did not allow such observations to be performed. It is worth noting that the above disadvantage of reflectorless total station - signal absorption by dark rocks, is equally true for laser scanners. Therefore, for such a survey, you need to have a scanner with a range of at least 1500 meters. Such devices are rare and quite expensive today. In addition, the use of scanners impedes the availability of vegetation. For these reasons, laser sanitization was not used to study the collapse zone and adjacent territories.

It is known that scanning based on the use of interferometry is also a remote surveying method [12]. This method has high accuracy (up to $0.1 \mathrm{~mm}$ ) in the study of open pits and dumps by comparing two surveys for different dates, but is not applicable for this survey. This technology is very promising and will certainly find application in the mining enterprises of Krivbass, but at the moment its application is complicated by the high cost of equipment and the need for constant protection.

The next of the methods under consideration, which has become the main one along with reflectorless total station, is the method of terrestrial stereotopographic survey. It is worth noting that for this area much later aerial surveys were performed, the results of which almost coincided with the ground. Based on its results, sections were added for which it was impossible to shoot using other methods.

Stereotopographic survey over the past ten years has become completely different. The development of terrestrial stereotopographic surveys in Kryvyi Rih quarries has had its ups and downs. This method is very popular in the seventies of the twentieth century, was practically no longer used in the mid-eighties and early nineties. There were many objective and subjective reasons for this, one of which was the physical and moral obsolescence of filming cameras and 
photogrammetric instruments for processing images. An important reason is the transition period in the development of Ukraine, which was characterized by the collapse of all economic relations and the decline of industry.

Stereotopographic survey in Ukraine acquired a new life with the advent and development of the digital photogrammetric station "Delta" and the software product Digitals, produced by GNPP "Analytics" and LLC "Geosystem". It should be remembered that in the Russian Federation at least three digital photogrammetric stations, such as Photomod, Talka and military developments, were also developed. But they were not widespread through an inflexible pricing policy or focus on the military-industrial complex. Therefore, with the acquisition in 2003 of the DFS "Delta" digital camera and in 2005 the EOS 350D digital SLR camera began a new but already digital ground-based stereotopographic survey. In the second decade of the 21 st century, there was another improvement related to the emergence of such software products as Pix4d, Photoscan, etc.

\section{Research of simultaneous surveying}

The need to have certain initial data for orienting the images and the fundamental difference in the obtained results of their processing often complicate the modern digital processing of images of old surveying. The difference is observed in many ways: in the ways of performing the necessary snapping to the image; in the number of survey stations, for example, before there were enough using two stations but now, by using of modern methods, they need more than three; in the need for GPS-snapping to the images. You can manually enter GPS tags in the EXIF data of images, but it will take a lot of time, for example, for 250 images to enter GPS coordinates. Therefore, the combination of new and old surveying in plan is very painstaking work. But the determination of the necessary data on the position of multiple points of terrain or object at one physical moment and the possibility of using them after a considerable period of time is one of the main advantages of photogrammetry.

The pictures were taken for the research of the collapse zone for the surveying dates of August 27, 2010 and July 31, 2019. The survey for August 27, 2010 consisted of 142 eight-megapixel images, of which 11 stereopairs were formed, and the rest of the images were used for the photo documentation of the terrain. The coverage area by stereo pairs is shown in Figure 3.

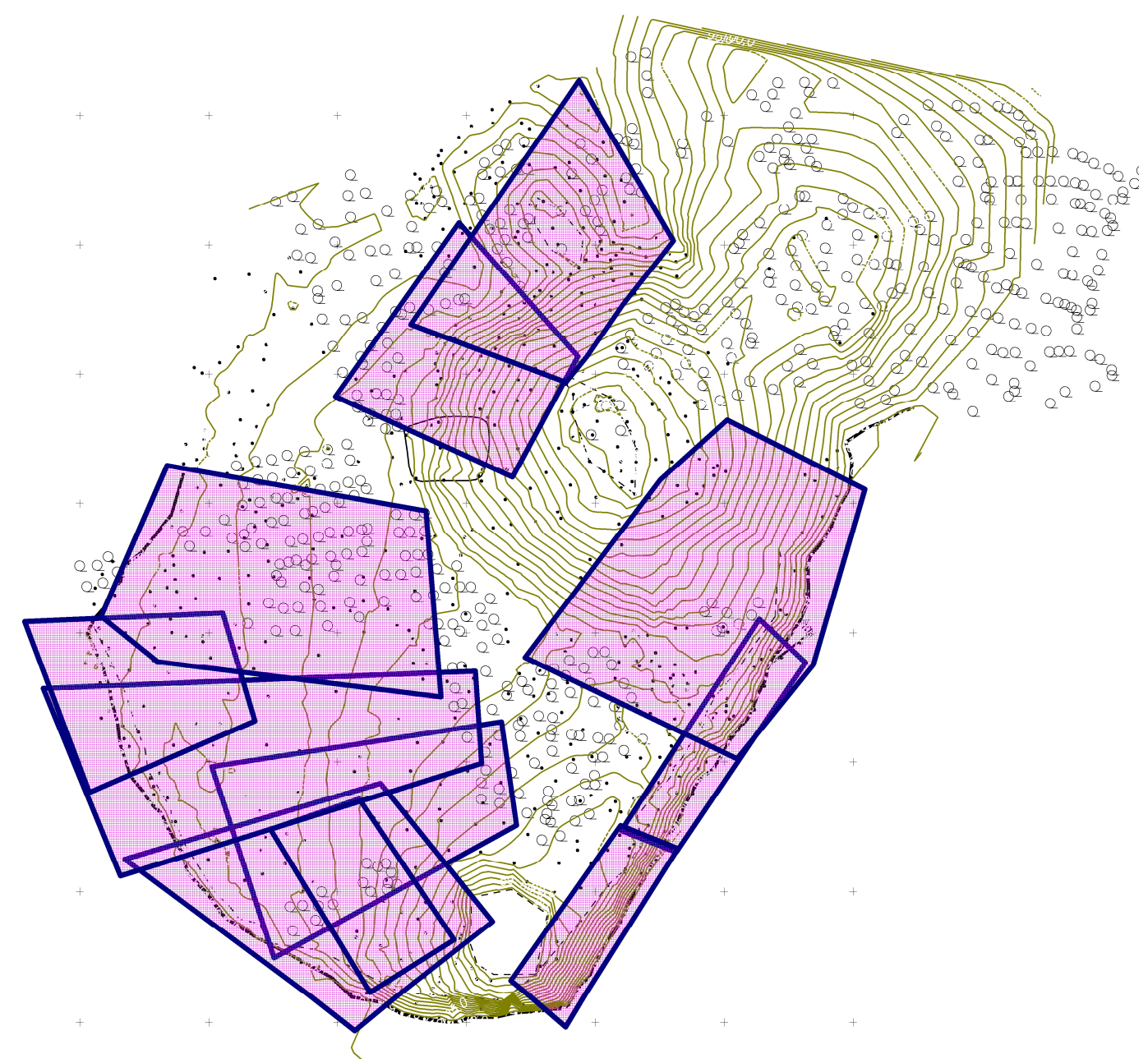

Fig. 3. The terrain coverage with stereopairs surveying for the date of August 27, 2010. 
As can be seen from the above scheme of covering the terrain with stereopairs, with an object area of $380,722 \mathrm{~m}^{2}, 196,412 \mathrm{~m}^{2}$ was covered with stereopairs, which is almost $52 \%$ of the total area. The accuracy of the planned position of the points due to errors in the external orientation of the stereopairs ranged from $0.01 \mathrm{~m}$ to $0.20 \mathrm{~m}$, which meets the requirements of the instructions for performing surveys performed for quarries, that is for the researched object.

Archival pictures of 2010 at that time met the requirements of stereotographic surveys, but preparing them for Pix4D or Agisoft Metashape software products took considerable time. When preparing the 2010 survey data for processing according to the program, most of the time was required to determine the coefficients needed to convert the coordinates from the conventional mine coordinate system to the given one. This is necessary to bring the coordinates of the points of the survey justification to a single coordinate system. For this purpose, three points were coordinated at the industrial site using the Topcon GPS receiver in the static mode and the coordinates of the points $\mathrm{Ct} 1, \mathrm{Ct} 2, \mathrm{Ar} 1$ and D1 were determined using the polar method from two points 92 and RPC0. Coordinates 91, 92 and $\mathrm{K} 1$ are determined with an accuracy of $3 \mathrm{~mm}$ in plan and $5 \mathrm{~mm}$ in height. Measurements at steps 92 and RPC0 were performed with a Sokkia SET630R total station in reflectorless mode. The errors in determining the coordinates of the points $\mathrm{Ct} 1, \mathrm{Ct} 2$, Ar1 and D1 ranged from $15 \mathrm{~mm}$ to $30 \mathrm{~mm}$ in the planned position and up to $30 \mathrm{~mm}$ in height. The choice of points $\mathrm{Ct} 1, \mathrm{Ct} 2, \mathrm{Ar} 1, \mathrm{D} 1$ was not accidental - these are practically the only contours that have remained unchanged for nine years and were recognized with high accuracy in the images for the start and end dates of the surveys (Fig. 4). The presence of green spaces greatly complicated the search for points that would be accurately recognized in the images for both dates.

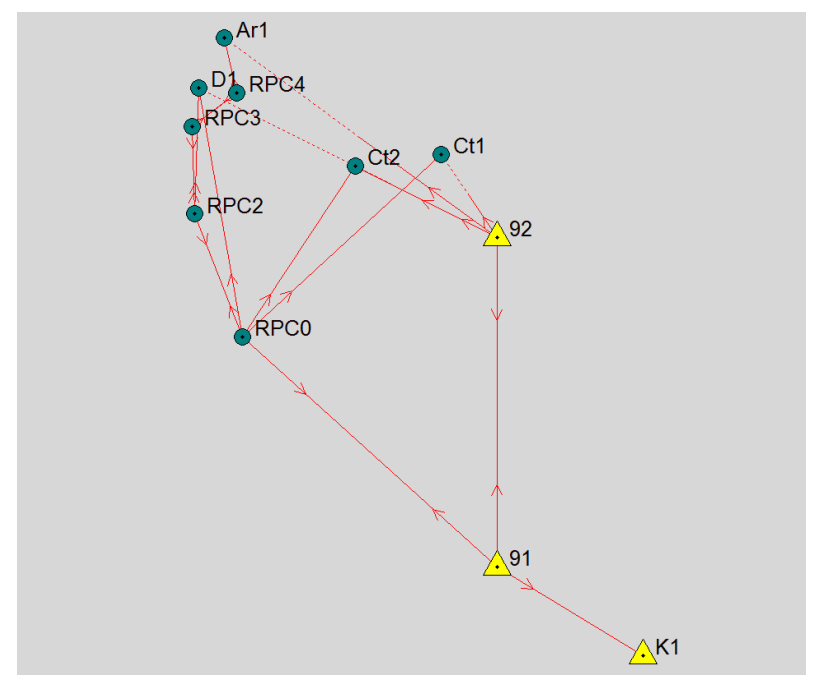

Fig. 4. The scheme of the points of reference and surveying justification.

As a result of processing the pictures taken in 2019 using the Pix4d program, the following errors in the position of the control points were obtained: along the $\mathrm{X}$ axis, not more than $139 \mathrm{~mm}$; along the $\mathrm{Y}$ axis $-138 \mathrm{~mm}$; along $\mathrm{Z}$ - no more than $33 \mathrm{~mm}$ (Table 1).

Table 1. The accuracy of determining the coordinates of control points according to the survey in 2019.

\begin{tabular}{|c|c|c|c|c|}
\hline GCP Name & Error X, $\mathbf{m}$ & Error Y, $\mathbf{m}$ & Error Z, $\mathbf{~ m}$ & $\begin{array}{l}\text { Verified/ } \\
\text { Marked }\end{array}$ \\
\hline 1 (3D) & -0.029 & -0.054 & 0.001 & $76 / 78$ \\
\hline $2(3 \mathrm{D})$ & -0.071 & -0.077 & 0.001 & $77 / 77$ \\
\hline $5(3 \mathrm{D})$ & 0.005 & -0.039 & 0.032 & $78 / 78$ \\
\hline 7 (3D) & -0.037 & 0.007 & 0.018 & $53 / 53$ \\
\hline $8(3 \mathrm{D})$ & 0.016 & -0.171 & -0.007 & $53 / 53$ \\
\hline $9(3 \mathrm{D})$ & -0.041 & 0.151 & 0.021 & $29 / 35$ \\
\hline $10(3 \mathrm{D})$ & 0.126 & 0.062 & -0.006 & $33 / 38$ \\
\hline $11(3 \mathrm{D})$ & -0.024 & -0.025 & -0.005 & $53 / 53$ \\
\hline $13(3 \mathrm{D})$ & 0.076 & -0.038 & 0.054 & $56 / 56$ \\
\hline $16(3 \mathrm{D})$ & -0.072 & -0.060 & 0.011 & 669 \\
\hline $17(3 \mathrm{D})$ & 0.139 & 0.138 & -0.033 & $61 / 62$ \\
\hline $18(3 \mathrm{D})$ & 0.014 & 0.050 & -0.027 & $47 / 47$ \\
\hline $19(3 \mathrm{D})$ & -0.062 & -0.142 & 0.006 & $44 / 46$ \\
\hline $20(3 \mathrm{D})$ & 0.130 & 0.114 & 0.029 & $56 / 58$ \\
\hline $21(3 \mathrm{D})$ & 0.043 & -0.103 & 0.070 & $70 / 70$ \\
\hline $22(3 \mathrm{D})$ & -0.136 & 0.078 & -0.093 & $57 / 57$ \\
\hline $24(3 \mathrm{D})$ & -0.120 & 0.033 & -0.044 & $54 / 55$ \\
\hline
\end{tabular}

The 2010 survey is characterized by a significantly smaller number of images and identifications, and the standard errors are in the range of $5 \mathrm{~mm}$ to $150 \mathrm{~mm}$ (Table 2).

Table 2. The accuracy of determining the coordinates of control points according to the 2010 survey.

\begin{tabular}{|c|c|c|c|c|}
\hline GCP Name & Error X, m & Error Y, m & Error Z, m & $\begin{array}{l}\text { Verified/ } \\
\text { Marked }\end{array}$ \\
\hline 1 (3D) & 0.135 & 0.228 & -0.049 & $14 / 14$ \\
\hline 2 (3D) & -0.031 & -0.032 & 0.049 & $14 / 14$ \\
\hline $\mathrm{m} 3$ (3D) & 0.107 & 0.020 & -0.046 & $15 / 17$ \\
\hline $\mathrm{m} 12$ (3D) & -0.147 & 0.044 & -0.053 & $10 / 10$ \\
\hline $\mathrm{m} 11$ (3D) & -0.118 & 0.053 & 0.106 & $18 / 18$ \\
\hline $\mathrm{m} 4$ (3D) & 0.073 & -0.546 & -0.063 & $17 / 17$ \\
\hline $7022(3 \mathrm{D})$ & 0.002 & -0.002 & 0.108 & $17 / 17$ \\
\hline
\end{tabular}

The points of the surveying object were referenced using GPS Receiver GP-E2 in the WGS 84 coordinate system (EGM 96 Geoid), and the identities were referenced in the Pulkovo 1942 / Gauss-Kruger zone 6 coordinate system (EGM 96 Geoid) by three-point direct intersection.

\section{Determination of deformations from the results of processing surveys for different dates}

To reduce the errors in determining the position of the points, the 2010 survey was divided into two parts - left and right, which were processed separately. Figure 5 shows a digital model in the form of a point cloud based on the results of the survey in 2019, and Figure 6 presents a digital model in the form of a point cloud according to the results of the 2010 survey.

The diagrams were constructed according to the results of processing the survey data characterizing the magnitude of the deformation of the pit side along three 
(X, Y, Z) or two (X, Y) axes (Fig. 7). The blue color shows the areas with minor changes - from $0.01 \mathrm{~m}$ to $0.10 \mathrm{~m}$, and shades of green show the areas with strains from $4 \mathrm{~m}$ to $6 \mathrm{~m}$ (the shade of green depends on the amount of deformation). The yellow and red colors show a deformation of more than 8 meters.
Figure 8 shows in different colors the strains obtained at the 2010 survey date. Analysis of the color change led to the conclusion that the deformation is concentrated in four zone.

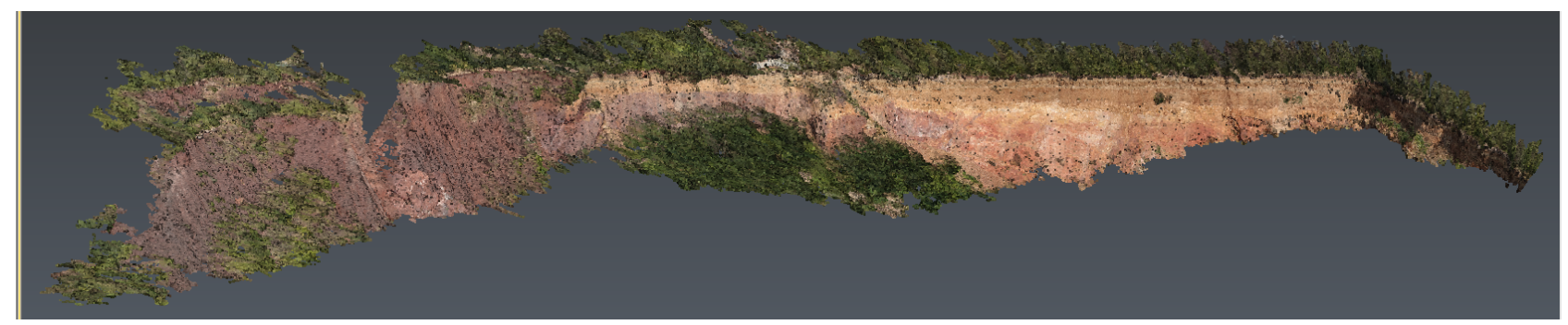

Fig. 5. The digital model created by the results of surveying in 2019 .

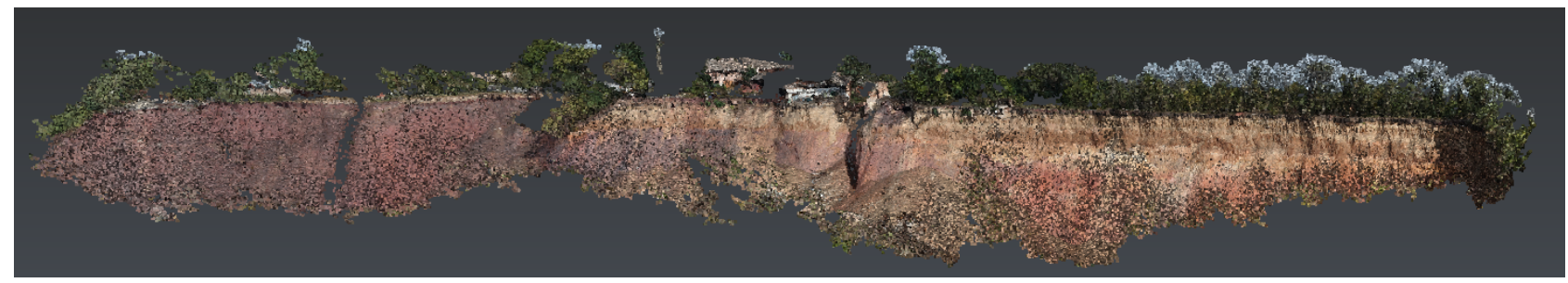

Fig. 6. The digital model created by the results of surveying in 2010 .

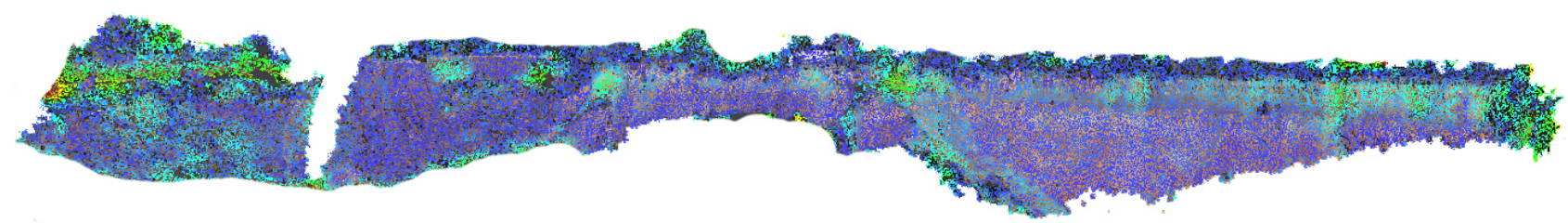

Fig. 7. The deformation of points on the side of the quarry according to the survey in 2019.

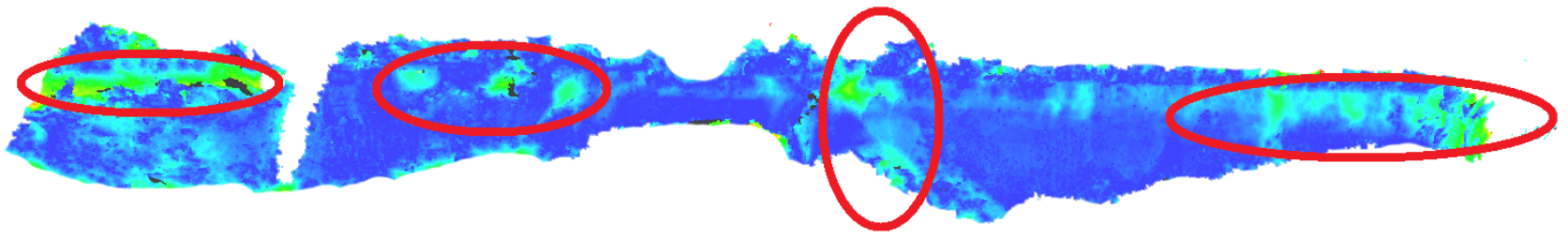

Fig. 8. Zones of maximum deformations.

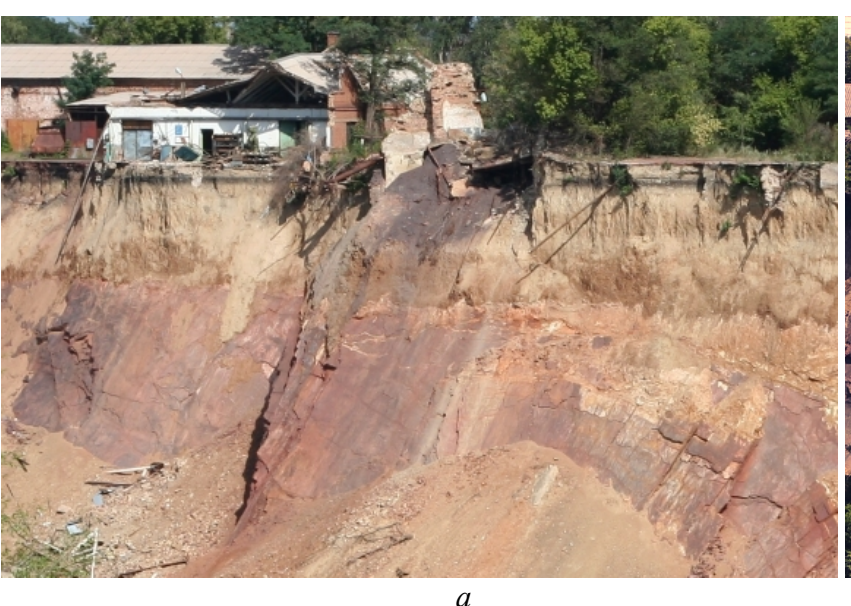

$a$

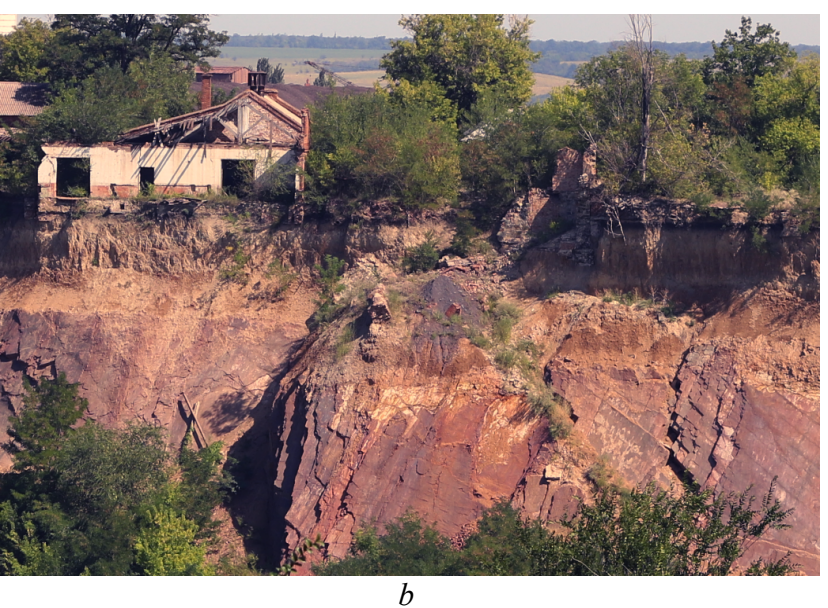

$b$

Fig. 9. Sites of the studied second (a) and third (b) zones. 
The first zone characterizes the sliding of the side with the formation of the approach. From the mine site, on the profile line adjacent to this zone, strains of up to $1000 \mathrm{~mm}$ in plan and $1500 \mathrm{~mm}$ in height were observed. Such deformations in magnitude led to significant changes in the surface, and for safety reasons the territory was fenced. Therefore, further observations are carried out only by remote methods.

The second zone combines three areas of rock mass scree with dimensions of about $15 \mathrm{~m} \times 10 \mathrm{~m} \times 5 \mathrm{~m}$, which occurred due to the flattening of an almost vertical side. The analysis showed that the deformation is facilitated by the geological structure of the site, as shown in the image of this site (Fig. 9a). The site is composed of bulk rather than rock formations.

The third zone is the site with the most large-scale changes. In this area, the promotion of the crow zone is the most significant and has affected buildings and structures. The site is composed of rocks. No cracks were observed on the site in 2010 (Fig. 9b), and in 2019 a large number of them appeared, which indicates active processes and array stress. Therefore, it was this area that was investigated in more detail. From the industrial site, profile lines were laid on this site to monitor the condition of the mountain massif and predict possible collapses.

The fourth zone is the epicenter of the funnel, so increasing it by 5 meters inland is logical. But only the upper layer underwent a change to a depth of 5-8 meters, bedrock is characterized by sufficient stability and a constant position for 9 years of observation.

The most efficient and accurate method for such studies can be considered laser scanning. To perform research on this object, a laser scanner with a range of 1

$\mathrm{km}$ is required. The performed studies have led to the conclusion that it is advisable to use ground-based digital photogrammetry for this method, which can replace laser scanning, and will also make it possible to assess the reliability of the results. Two surveys were performed in 2019 for this with an interval of seven days. A short interval between surveying made it possible to use the same points as signs. It was found that under almost identical surveying conditions, the errors of the initial data can be neglected. With sufficient accuracy $(3-5 \mathrm{~cm})$, a uniformly blue surface of changes is observed.

Surveying for the date of August 21, 2019 was performed from 11 survey stations that were selected with the fulfillment of the security conditions for the work of the performer (Fig. 10). The selected observation conditions did not allow us to arrange the bases of surveying perpendicular to the object. Therefore, the pictures were taken with a significant bevel to the right (more than 600), which negatively affected the accuracy of the results.

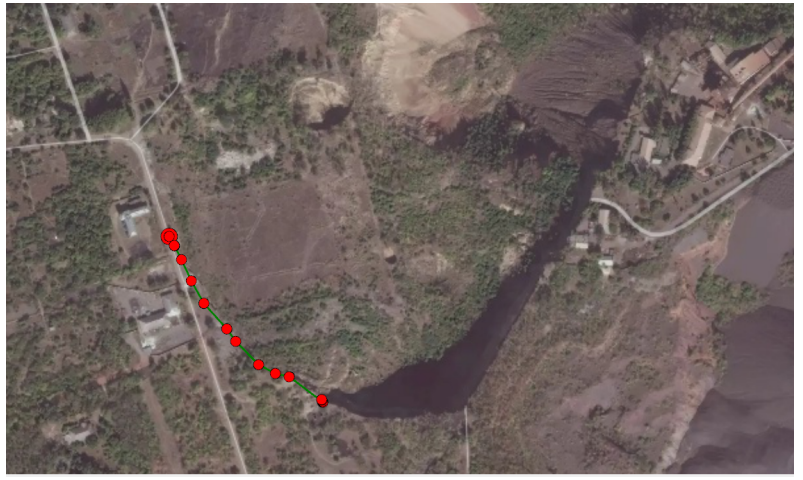

Fig. 10. The scheme of the surveying bases location.

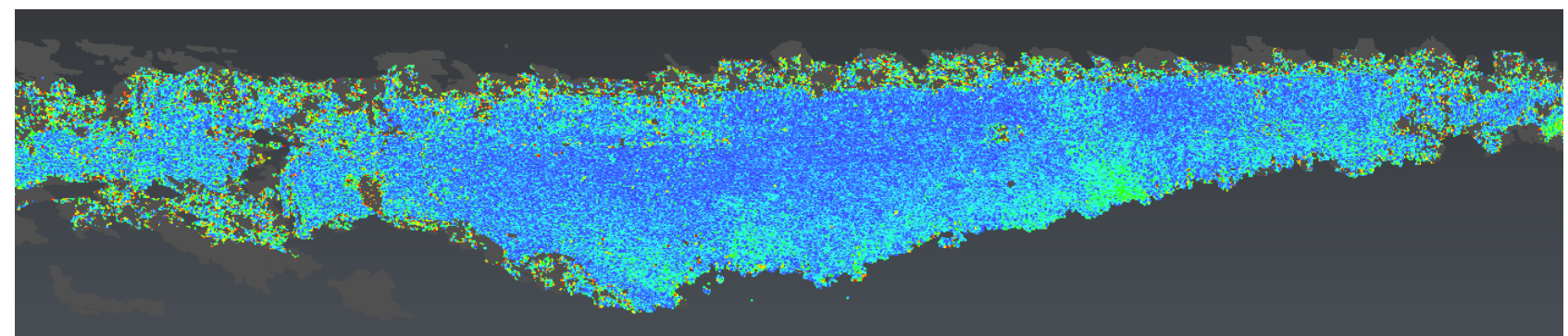

Fig. 11. The position of points with different errors in determining spatial coordinates.

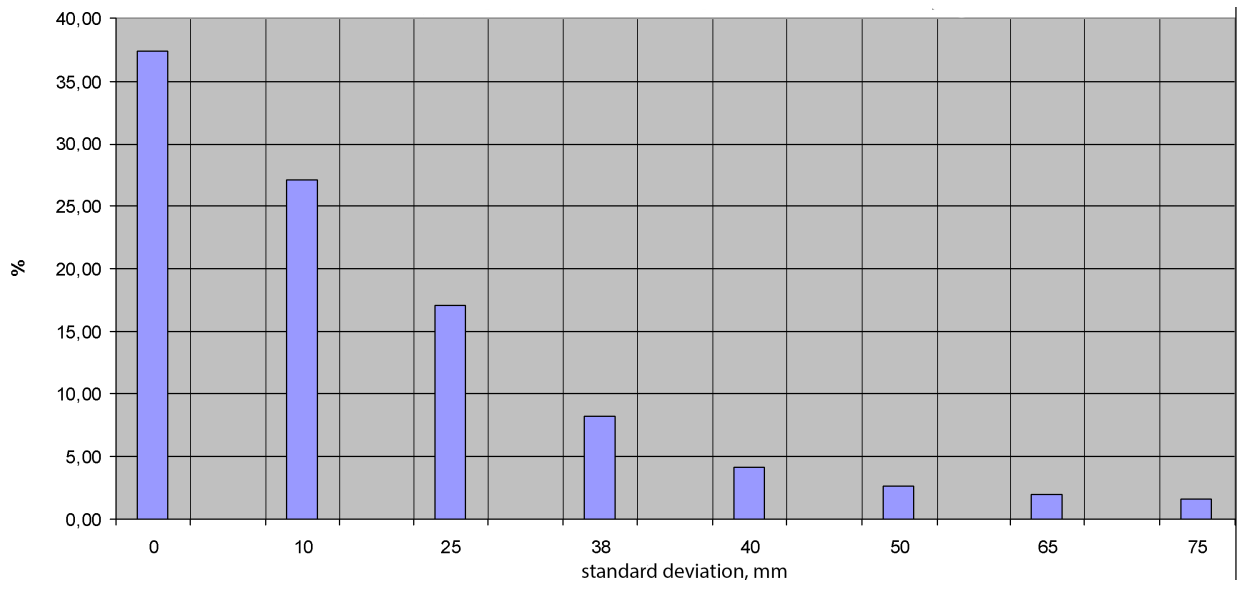

Fig. 12. The distributions of errors in determining the position of points. 
The above figure characterizes the accuracy of determining the position of points based on the results of ground-based stereo surveys in the study of slope deformations. In the figure, the blue color corresponds to the studied points, which have a complete coincidence of the spatial position for two dates with an accuracy of 0 $\mathrm{mm}$ to $10 \mathrm{~mm}$, which is $37.4 \%$ of the total number of points. The number of points whose spatial position coincides over two dates with an accuracy of 10 to $25 \mathrm{~mm}$ is $27.0 \%$. The graph (Fig. 12) shows data on the number of points in percent, the accuracy of determining the positions of which correspond to different values.

As can be seen in the graph, $89 \%$ of all points have errors in determining the position of points up to $50 \mathrm{~mm}$ and $11 \%$ - from $50 \mathrm{~mm}$ to $75 \mathrm{~mm}$. Most of the points with errors from $50 \mathrm{~mm}$ to $75 \mathrm{~mm}$ correspond to areas with vegetation; therefore, when cleaning a cloud of points using a filter, their number decreased by three times and corresponds to $3 \%$.

\section{Conclusion}

When studying the deformations of the ground surface in the collapse zone from the Ordzhonikidze mine, a digital survey was used, which made it possible, using a 24megapixel camera with distances of 600-700 meters from the object of study, to obtain the accuracy of determining the spatial coordinates of cloud points from $0 \mathrm{~mm}$ to $50 \mathrm{~mm}$. The resulting accuracy is lower than the accuracy of laser scanning, but has advantages when shooting from large distances to the subject. Further research is aimed at improving the methodology for performing survey work and photogrammetric image processing, which will improve the accuracy of determining the spatial coordinates of the studied points and the effectiveness of digital shooting.

\section{References}

1. S.S. Peng, Society for Mining, Metallurgy, and Exploration 161 (1992)

2. F. Carvajal, F. Agüera, M. Pérez, ISPRS XXXVIII1/C22, 201-206 (2011)

3. V. Peterman, ISPRS, XL-1/W4, 215-218 (2015)

4. D. Beregovoi, Montanuniversität Leoben department of mineral resources engineering (2015)

5. M. Pollefeys, Visual 3D Modeling from Images (University of North Carolina, 2002), pp. 55-65 https://www.cs.unc.edu/ marc/tutorial.pdf. Accessed 21 Mar 2020

6. V.O. Kalinichenko, O.V. Dolgikh, L.V. Dolgikh, E3S Web of Conferences 123, 01047 (2019). doi:10.1051/e3sconf /201912301047

7. M. Stupnik, V. Kolosov, V. Kalinichenko, S. Pismennyi, in Progressive Technologies of Coal, Coalbed Methane, and Ores Mining (2014), pp. 2530. doi:10.1201/b17547

8. M.I. Stupnik, V.O. Kalinichenko, S.V. Pysmennyi, O.V. Kalinichenko, Naukovyi Visnyk
Natsionalnoho Hirnychoho Universytetu 4, 21-27 (2018). doi:10.29202/nvngu/2018-4/4

9. E.J. Lee, S.Y. Shin, B.C. Ko, C. Chang, Infrared Phys. Technol. 78, 223-232 (2016)

10. J. Suh, Y. Choi, Environ. (Earth Sci. 2017), 76 (2013)

11. F. Nex, F. Remondino. Applied Geomatics 6(1), 115 (2013)

12. R.N. Nof, G. Baer, A. Ziv, E. Raz, S. Atzori, S. Salvi, Geology 41, 1019-1022 (2013) 